\title{
A Journey to BSO: Evaluating Earlier and More Recent Ideas of Mario Bunge as a Foundation for Information Systems and Software Development
}

\author{
Roman Lukyanenko(凶) \\ HEC Montreal, Montreal, QC, Canada \\ roman.lukyanenko@hec.ca
}

\begin{abstract}
A prominent theoretical foundation for IT analysis, design and development is general ontology - a branch of philosophy which studies what exists in reality. A widely used general ontology is BWW (Bunge-Wand-Weber) - based on ideas of the philosopher and physicist Mario Bunge, synthesized by Wand and Weber. It is regarded as a major contribution to conceptual modeling, database design, data collection design and information quality, as well as theory of IT. At the same time, the ontology was founded on an early subset of Bunge's philosophy and Bunge's ideas have evolved since then. An important question, therefore, is: do the more recent ideas expressed by Bunge call for a new ontology? In this paper we conduct an analysis of research by Bunge aiming at addressing this question. We compare the constructs of BWW with what we call Bunge's Systemist Ontology (BSO) - a new ontology based on broader and more recent ideas developed by Bunge. Informed by this comparison we offer suggestions for ontology studies as well as future applications of Bunge in conceptual modeling and other areas of IT.
\end{abstract}

Keywords: Ontology $\cdot$ Upper-level ontology $\cdot$ Bunge $\cdot$ Bunge-Wand-Weber ontology $\cdot$ Bunge's Systemist Ontology $\cdot$ Conceptual modeling $\cdot$ IT development

\section{Introduction}

With the increased reliance on information technology (IT), grows the importance of building IT based on solid foundations [1,2]. Historically, one of the most prolific and effective references for IT analysis, design and development has been ontology. In this paper we focus on general ontology - a branch of philosophy which studies what exists in reality (and what reality is) [3, 4] - rather than a domain ontology - a description (often formal) of constructs in a particular domain (e.g., ontology of Software Defects, Errors and Failures, see [5] or ontology of research validity [6]) [7].

A general (also known as foundational or upper level) ontology offers IT development theoretically grounded (i.e., based on established knowledge from other disciplines as psychology or physics), consistent, formalized and rigorous meaning for the basic notions of what exists in reality and thus in a domain of IT. As such, ontological studies are 
now widely embraced by the IT community. Applications of ontologies are especially prolific in research on semantic web (which aims to move beyond syntactic matches to deeper interoperability), and conceptual data and process modeling (which develops representations of application domains and user requirements), but have also been used in knowledge management, artificial intelligence, interface design, data collection processes, database schema integration, analysis of software performance, information quality, among others [4, 8-14]. Empirical benefits of adopting a particular domain ontology (e.g., in the design of conceptual modeling grammars or improving quality of data produced by an IT) have been documented [8, 15-19].

Considering the demonstrable benefits of general ontologies, research has proposed a number of general ontologies to be used for IT analysis, design and development, such as Unified Foundational Ontology (UFO) [20], social ontology of Searle [21], General Formal Ontology [22], DOLCE [23]. A prominent ontology is BWW (BungeWand-Weber) - based on ideas of the philosopher and physicist Mario Bunge (1919-Feb 2020), synthesized by Wand and Weber [24, 25].

The BWW is widely regarded as major contribution to theory and practice of IT and conceptual modeling, at it has been informing theoretical, empirical and design works across a wide range of disciplines [26, 27]. At the same time, the ontology has been criticized e.g., [28], especially on grounds related to the assumptions underlying the ontology rooted in philosophical beliefs of Bunge.

Notable, BWW was developed on a subset of Bunge's ontology $[29,30]$ which is now over 40 years old (i.e., 1977 and 79). In the 40 years since the publication of the two primary sources of BWW [29, 30], Bunge published over 100 books and 300 papers [31], in which his ideas were further expanded, refined, and sometimes, altered. Several question, therefore, arise:

Research Questions (RQs): is there a need for a revision to the original BWW? Are statements such as "Bunge believes the world is made of things" justified in light of more recent publications? Should this be a minor, or a major revision? Does it result in an expansion of BWW e.g., [32], or do the ideas expressed (since 1979) by Bunge call for a completely new ontology?

In this paper we provide results of a first phase of the project aiming at addressing these questions. In this phase we compare key constructs of BWW with what we coin Bunge's Systemist Ontology (BSO) - a more recent set of ideas developed by Bunge since the volumes which formed basis for BWW. Informed by this analysis we offer suggestions for future research on both development of ontology as well as use of Bunge in conceptual modeling and other areas of IT.

\section{Background: Bunge-Wand Weber Ontology}

In a recent essay, Yair Wand and Ron Weber offer a first-hand account [26] of what motivated them to pursue their program of grounding information systems (IS) research in foundational ontology and how they developed a set of theories (e.g., theory of ontological expressiveness, representation model, good-decomposition model) based on what became known as Bunge-Wand-Weber ontology. Although they consulted other sources, the primary foundation of BWW are two seminal manuscripts on ontology by Bunge $[29,30]$, part of his eight volume Treatise on Basic Philosophy. 
Briefly, following philosophy of Bunge, BWW [24, 25] argues that the world is made of things - substantial individuals - which possess properties; things may compose forming composite things, interact with one another, leading to acquisition of new or loss of existing properties, resulting in events; sets of things from systems. Properties are not directly accessible to human observers, resulting in the notion of attributes; attributes which humans ascribe to things may or may not be accurate or complete representations of the underlying properties. In sum, the key constructs from Bunge which have been adopted into BWW are: thing, property, attributes, functional schema, state, law, state space, event, history, coupling, system, class, kind, and their derivatives (e.g., lawful state space) i.e., see Table 1, p. 222 [33] and [34].

The BWW ontology and the theories, models and methods derived from it, have been used widely in conceptual, empirical and design work in information systems, conceptual modeling, software engineering and other areas [26], making it among the most important developments in the area of ontology in disciplines of IT [35].

Despite the prolific use of BWW (for most recent reviews, see [35, 36]) the ontology has been criticized for its narrow physicalist focus, lack of attention to social and psychological phenomena, as well as postulates which may be problematic for modeling certain type of domain rules (e.g., BWW proscribed optional properties, denied independent existence of properties, and properties of properties) $[4,21,28,37]$.

Despite the many debates centered on BWW, a generally overlooked issue is that the original ontology is based on select references from Bunge. Although there have some attempts at expanding BWW to incorporate other ideas of Bunge [32], these were still narrow in scope and did not see widespread adoption compared with BWW.

The basis for BWW have been two, albeit seminal and focused on ontology, manuscripts by Bunge. However, as Bunge frequently noted, ontology is inseparable from other beliefs, such as on how to obtain knowledge in the world [38]. Indeed, the Treatise contained many additional beliefs, including on matters of semantics, epistemology, methodology, ethics, technology, among others.

Additionally, in the over 40 years since the publication of the 1977 and 79 volumes (and even since the last book of the Treatise - on ethics [39]), Bunge published over 400 manuscripts, in which his ideas were further expanded, refined, and sometimes, altered ${ }^{1}$. Some of these more recent ideas were of great potential relevance to IT, as they directly dealt with issues of information technology e.g., [41].

Considering the broad and profound impact BWW had on the disciplines of IT, such as conceptual modeling, an important question to ask is: Can we further IT research and practice by incorporating these, more recent views and beliefs of Mario Bunge? In order to answer this question, it is first incumbent to assess the extent to which the original basis for BWW and the more recent thinking agree and diverge.

\footnotetext{
${ }^{1}$ An example of a reversal is Bunge's admiration for Marxism-Leninism (an extensive set of beliefs transcending the general public's most familiar ideas about politics and economy). It was Bunge's first major philosophical doctrine, according to his own confessions but over the years he distanced himself and then ended up being a vehement critic of Marxist-Leninist "ontology and politics" [31, p. vii], [40].
} 


\section{Constructing Bunge's Systemist Ontology}

The task of understanding the differences between Bunge's ideas enshrined in BWW and his other, and more recent thinking, meets a challenge: the ideas which formed BWW were carefully distilled, while the more recent thinking was not. Although based on two volumes, BWW was founded on a self-contained Treatise on Basic Philosophy which developed and present ideas systematically and with great internal consistency: beginning with semantics [42], then ontology [29], followed by epistemology [43], methodology [43] and ethics [39]. In contrast, the more recent thinking of Bunge (e.g., since the Treatise) has not been assembled into a dedicated, self-contained single compendium. Rather is a collection of over 400 essays, papers and books (e.g., [38, 41, 44-46]), which require dedicated synthesis ${ }^{2}$.

To answer the RQs of the paper, we engaged in a comprehensive and systematic effort to catalog and present these beliefs, a project which was done over a period of five years (2015-2020), covering up to the last known publication by late Bunge.

The procedure was conducted in the following steps: First, we began to assemble a library of publications by Bunge and conducted a scoping survey of the writing to gain a preliminary idea of the extend of alternations and expansions compared with the Treatise. Second, half-way into the process, the author contacted Mario Bunge, who kindly agreed to meet and provided a general overview of his earlier and most recent thinking and answered numerous clarifying questions. Third, we reviewed all pertinent publications using GoogleScholar and [31] as the sources ${ }^{3}$. Fourth, we followed the logical path outlined in the Treatise (i.e., ontology, epistemology, methodology and ethics) and re-iterated and explained by Bunge in other sources e.g., [38] to catalog the ideas beginning with basic assumptions about reality, followed by the problem of knowledge of reality and then the application and use of the knowledge by society (e.g., in policy-making, science and daily life). Fifth, we began synthesizing the ideas, favoring the most recent publications e.g., $[45,46]$ as the primary signal and referencing earlier publications e.g., [38], Bunge's own memoirs [40], and authoritative studies on Bunge [31], for clarification or expansion of ideas, when needed ${ }^{4}$.

The result is a systematic synthesis of Bunge's publications aimed at distilling and presenting a single, coherent and consistent set of beliefs with the aim of using these ideas in the context of IT. As mentioned, Bunge kindly clarified some of the ideas of his ontology and also shared a copy of his most recent and (as of February 2020) unpublished manuscript. However, all claims made here are justified either through direct references to published works by Bunge or are explicitly noted as author's own inferences, and derivations. To report the findings, we analyze the constructs of BWW presented in see Table 1, p. 222 [33] compared with what we refer to as Bunge's Systemist Ontology

\footnotetext{
${ }^{2}$ For example, although Bunge has made a stronger emphasis toward systems, his recent writing is still rich in references to things, including in the same texts where he talks about systems being primary existents and preferable to notion of things (e.g., [45, p. 174]).

$3 \mathrm{https}$ ://scholar.google.com/citations?user=7MmcYgEAAAAJ\&hl=en\&oi=ao.

${ }^{4}$ For example, whereas Bunge describe systems in [44, p. 270] (among many other sources), to find more detailed discussion of properties of systems, one can consult, for example, [38, pp. 10-19].
} 
(BSO) which as we argue later is a new ontology. Bunge uses multiple labels to describe his set of beliefs (e.g., "emergentist materialism" [47], "hylorealism" [38, p. 27]), but the most frequently used appears to be "systemism" [30, 46, 48].

\section{Bunge's Systemist Ontology Vs Foundations of BWW}

The BSO claims reality is all that we know to exist and distinguishes five "kinds" or "levels" of reality, including physical, chemical, biological, social and technical [44, p. 25]. These levels may have different actual or perceptible to human properties or events, but all are ultimately grounded in the underlying physical level.

The BWW ontology postulated that reality is made of things, which have properties [29, pp. 26-29]. Things are "substantial individuals", which could be composed of other individuals or be simple [34, p. 126]. A set of things forms a system [30, p. 6].

Although the notion of system exists in BWW, through the passage of time, BSO has been adopting a new postulate that under some interpretation inverts the relationship between things and systems. In BSO, Bunge believes the world is made of systems: "everything is a system or a component of a system" [46, p. 23]. Thus, Bunge argues, "every thing is either a system or a component of such", "every construct is a component of at least one conceptual system", "every symbol is a component of at least one symbolic system" [44, p. 266]. A thing is a type of system (although this view is not consistent through Bunge's recent wring).

By drawing upon recent advances in physics, especially particle physics that Bunge followed closely e.g., [49], Bunge [45] explains (p. 174, emphasis added):

The word 'system' is more neutral than 'thing', which in most cases denotes a system endowed with mass an perhaps tactually perceptible; we find it natural to speak of a force or field as a system, but we would be reluctant to call it a thing. By calling all existents "concrete systems" we tacitly commit ourselves in tune with a growing suspicion in all scientific quarters - that there are no simple, structureless entities.

Systemism doesn't suggest things no longer exist, but for Bunge it appears more productive to think about the basic elements of the world as systems, rather than things. Yet, it is notable that he has not fully committed himself to this thinking as he admits a possibility of atomic things (i.e., "non-systems") [48, p. 148]:

Only particle physicists study non-systems, such as quarks, electrons, and photons.

But they know that all such simple things are parts of systems or will eventually be absorbed by some system.

Yet, as conceptual modeling and many other areas of IT do not engage with quarks, electrons, and protons (perhaps the progress in quantum computing may change this in the future), effectively these disciplines may disregard the caveat in [48, p. 148] and treat all existents of interest as systems. Thus, we can conclude that in BSO, the world is made of systems. 
For Bunge, systmism holds numerous advantages, as it conceptually lies in between individualism (which under-represents internal structures of a system, its relationship with outer environment, its levels of composition and emergence) and holism (which is not interested in the components and specificity of subsystems). For Bunge, systemism represents the best of these two ideas, without sacrificing the benefits of each [48]. This is how Agazzi, a friend and close associate of Bunge, summarizes his views, which he debated with Bunge extensively over the years [50, p. 224]:

[Bunge] explicitly presents his position (which he calls "systemism") as intermediate between two erroneous extremes, "atomism" and "holism". The weakness of atomism resides in that it ignores the relevance of properties and especially relations, without which it is impossible to distinguish a single "aggregate" from a "system". The weakness of holism resides (according to Bunge) in its pretension that the knowledge of the whole must precede and make possible the knowledge of the parts. Systemism avoids both mistakes by recognizing that the whole "results" from the correlation of its parts and at the same time has influence on their functioning.

Bunge believes, systems are always composed of components or parts [46, p. 23]. However, it is not clear what the construct of "part" or "component" mean - we have not seen their definition in Bunge's writings. A way to avoid this problem is to recognize, one again, that in the domains of interest to IT, parts or components of systems are systems themselves. This is an important realization, as it liberates the field of IT from the need to resolve the fundamental ontological status of the "component" or "system part".

Over the years, Bunge developed and expanded his ontology of systems. Thus, in the Treatise, Bunge postulated that any system should have "a definite composition, a different environment, and a different structure. The composition of the system is the set of its components; the environment, the set of items with which it is connected; and the structure, the relations among its components as well as among these and the environment" [30, p. 4].

In later writings, this initial idea was developed into a CESM model, which in addition to the composition, environment, and structure (present in BWW), added "mechanism" [48]. Mechanism is defined as "characteristic processes, that make [the system] what it is and the peculiar ways it changes" [38, p. 126]. To illustrate, Bunge provides an example of a traditional nuclear family [38, p. 127]:

Its components are the parents and the children; the relevant environment is the immediate physical environment, the neighbourhood, and the workplace; the structure is made up of such biological and psychological bonds as love, sharing, and relations with others; and the mechanism consists essentially of domestic chores, marital encounters of various kinds, and child rearing. If the central mechanism breaks down, so does the system as a whole.

Adopting BSO in the context of IT allows to potentially remove the notion of a thing from the ontology, simply replacing it with the system construct. The inversion of the relationship between things and systems, and the potential obviation of the need for 
things in BSO, represents a major change, as the construct of thing has been a founding one for BWW and has been the conceptual foundation for many studies which adopted BWW [19, 51].

However, as effectively, things in the social and technical levels of early Bunge were effectively systems [30], this change can be easily accommodated by much of prior work which used BWW with a mere replacement of a label.

As systems replace things, this results in a reduction of complexity of BWW ontology that dealt with the relationship between things and systems (e.g., obviating the need for constructs such as "composite thing" or "properties of things"). For example, BWW defines internal event as "an event that arises in a thing, subsystem, or system" [33, p. 222]. This definition can simply state that an internal event is an event that arises in a system. However, note, an ontology that uses systems as its fundamental ontological primitive, would probably borrow other constructs related to systems, which are beyond the BWW (e.g., CESM).

As in BWW, BSO continues to uphold the beliefs about the relationship between systems and properties. Systems have properties. Properties do not exist outside of systems [45, p. 175]: "Property-less entities would be unknowable, hence the hypothesis of their existence is untestable; and disembodied properties and relations are unknown." As in BWW, properties according to BSO do not exist in themselves: "However, ... can be material only derivatively, that is, by virtue of the materiality of the things involved: there are neither properties nor relations in themselves, except by abstraction." [38, p. 11].

Notions of classes and kinds are used in BSO, but somewhat differently compared with BWW. In BWW, classes are sets of things sharing "a common property", whereas kinds are sets of things which share "two or more" property [33, p. 223]). Systems with "one of more" common properties in BSO [44, p. 111], form classes and those with properties which are interrelated, form kinds [38, p. 13].

The greater emphasis on systems carries other implications, as this new postulate is propagated throughout most of Bunge's recent beliefs. According to BSO, some but not all (an important caveat cf. BWW) systems undergo change, resulting in emergence (addition of new) or submergence (loss of old) of properties. To account for this, BSO continues to use the construct of state. Bunge [45, p. 171] defines a state as "the list of the properties of the thing at that time" - a definition nearly identical to that in BWW [29, p. 125]. A state can describe multiple properties (at the same moment in time) [38]. A given system has the properties of its subsystems, as well as its own, termed emergent properties (and idea unchanged since BWW), but now gaining greater focus in BSO, as a key implication of systemism.

Whereas per BWW, Bunge applies the notion of a state to all things [29, p. 123], in BSO, Bunge [38] makes an important distinction between systems which undergo change and those do not. In BWW, a set of postulates deal with changes of states (i.e., events) and how the properties which make up the states are perceived by humans (i.e., attributes) [29]. However, for BSO these constructs do not apply to all systems.

Bunge distinguishes two kinds of system: conceptual and concrete [44, p. 270]. A conceptual (or formal) system is a system all the components of which are conceptual (e.g., propositions, classifications, and hypothetico-deductive systems-i.e., theories). 
This is contrasted with concrete (or material) systems which are made of concrete components (i.e., subsystems, such as atoms, organisms, and societies), meaning that these components may undergo change..$^{5}$

What distinguishes concrete and conceptual systems is the essential property of mutability - a key element of BSO - which only concrete systems possess: "mutability is the one property shared by all concrete things, whether natural or artificial, physical or chemical, biological or social, perceptible or imperceptible" [38, p. 10]. Bunge thus explains that changes in systems may only occur if the systems are concrete [38, p. 11]:

heat propagation, metabolism, and ideation qualify as material since they are processes in material things. By contrast, logical consistency, commutativity, and differentiability can only be predicated of mathematical objects.

Concrete systems change in the virtue of energy transfer. For Bunge, "the technical word for 'changeability' is energy" [38, p. 12], such that:

To repeat, energy is not just a property among many. Energy is the universal property, the universal par excellence.

We thus obtain a more formal definition of a concrete system in BSO as a system that has energy [38, p. 12].

The BSO dedicates considerable time to the notion of energy, as it underlies Bunge's thinking about (new to BWW) constructs of causality, trigger and chance. He analyzes these notions relative to different kinds of energy, including mechanical, thermal, kinetic, potential, electric, magnetic, gravitational, chemical (e.g., in [38]). Thus, per BSO, when systems interact, they transfer energy from one to another. This leads to change in states of things, as they acquire or lose their properties. This produces events and processes. Energy when paired with artificial code may transmit information (new to BWW constructs, and of special relevance to the field of IT).

The consequence of re-definition of systems as either energy-bearing or not, makes another major change compared with BWW. Thus, while in BWW an event has been understood as a "change in state of a thing" [33, p. 222], in BSO, event in understood in terms of energy, thus being only applicable to concrete systems ${ }^{6}$. Bunge views event as an energy-involving construct [38, p. 91]:

Event $\mathrm{C}$ in thing $\mathrm{A}$ causes event $\mathrm{E}$ in thing $\mathrm{B}$ if and only if the occurrence of $\mathrm{C}$ generates an energy transfer from A to B resulting in the occurrence of $\mathrm{E}$.

Multiple events form processes (a new construct for BWW): defined as "a sequence, ordered in time, of events and such that every member of the sequence takes part in the determination of the succeeding member" [45, p. 172].

\footnotetext{
${ }^{5}$ Bunge [44, p. 270] also distinguishes a symbolic (or semiotic) system as a type of a concrete system some components of which stand for or represent other objects (e.g., languages, computer diskettes, and diagrams).

6 This may potentially resolve the criticisms levied against Bunge's ontology by as being too physicalist $[21,28]$ - original ideas of Bunge captured in BWW without explicit qualification have indeed been casted by BSO as belonging to only material reality.
} 
The demarcation between events applicable to concrete vs conceptual systems, affects the definition of the notion of law, which is applicable to concrete systems only. Laws are stable patterns which hold "independently of human knowledge or will" [44, p. 27]. In BSO, conceptual systems do not obey laws, but rather obey rules of logic [38, p. 19] - a new concept for BWW.

The BSO then draws a very close connection between ontology and epistemology, a connection which is not as evident in BWW. BSO's epistemology is vast and extensive and connects his ontology to other philosophical beliefs differently compared to BWW. Whereas in BWW, the connection is made via the constructs of attributes (i.e., properties as seen by people and model things), in BSO the connection is again, via systems.

For BSO, an event or a process as it appears to some human subject is termed phenomenon [45, p. 173] (new to BWW construct). It is an occurrence registered by the sensory apparatus of humans or other animals triggered by a change or a serious of changes in the state of a concrete system. For example, the rising of the sun or inauguration of the president calls a complex chain of events in the attentive, perceptive, cognitive and other biological and mental processes of the people who experience these events (either directly or via a signal, such as radio, Internet or television). Phenomena are always "in the intersection of the external world with the cognitive subject" [45, p. 173].

Events, processes, phenomena, and concrete systems are instances of the mental concept of fact - i.e., they lie "in the extension of the concept of fact" [45, p. 174]. Facts are kinds of objects - "whatever is or may become a subject of thought or action" [45, p. 174] i.e., "known or assumed - with some ground - to belong to reality" [45, p. 171]. Thus, through the notions of facts, BSO connects the fundamental ideas about the composition of reality to the mental world of humans.

As Bunge stresses, what can be observed as phenomena is a small fraction of the facts constituting the object of an investigation; "the observable facts or phenomena are documents suggesting or confirming the existence of more interesting facts behind" [45, p. 177]. Facts are iceberg-like: they are mostly submerged under the surface of immediate experience and, furthermore, the phenomena are often quite different from the concrete systems they are based on. Consider for example the difference between the visual sensations caused by aurora borealis and the actual chemical, magnetic, and other physical processes involved in the unraveling of this concrete system.

Thus, the "submerged" portion of facts must be hypothesized and, in order to test such hypotheses, definite relations between the unobserved and the observed must be added, by which the observed can count as evidence for or against the existence of the hypothetical unseen, and the unseen can explain what can be seen. These relations are represented by hypotheses and theories [45, p. 177].

It is a subject of centennial debates in philosophy whether human observers have access to more than just phenomena. The position of the phenomenalism holds that only direct sensations and experiences are knowable [52]. In contrast, various strands of realism generally believe that reality beyond sensations can be known [53]. This can be accomplished with the aid of experimentation, theory testing, imagination and logical inference. Bunge per BWW and BSO is a proponent of the latter [45]. For Bunge [45], the 
pragmatic benefit of realism is that it encourages thinking and action beyond sensations and encourages an active stance toward reality.

There is no "end" of the BSO per se (recall, BSO is not published in a self-contained treatise), as Bunge continuously stresses the interdependency between ontology and other beliefs, thus we draw a demarcation based on constructs in BWW [33]. We note, Wand and Weber engaged with other ideas of Bunge, as did other scholars e.g., [32, 54], and acknowledged the existence of other constructs and more recent set of beliefs. As they note, Bunge "has written extensively about social phenomena using constructs based upon his ontology (e.g., Bunge, 1998)" [26, p. 6]. Yet, much of IT community adopted the views of Bunge stemming from BWW, making this an important benchmark comparison.

\section{Discussion and Implications}

The Bunge-Wand-Weber ontology has been a seminal ontology having demonstrable and broad impact on various disciplines of IT. It has been proven effective at guiding conceptual, empirical and design research. The success of BWW motivates our efforts to examine the extent to which we could benefit from more recent ideas and beliefs of Mario Bunge. Based on our analysis above, we can draw the following conclusions and suggest several implications for future studies.

Frist, it is evident that more recent thinking by Bunge remains partially consistent with BWW. In particular, BSO continues to adhere to the tenets of scientific realism and grounds thinking into interpretation of the state-of-the-art knowledge in physics and other disciplines. Many ideas in BSO have not changed compared to BWW; these include the denial of the existence of properties (with known implications for conceptual modeling research, such as the problem of optional properties or properties of properties $[15,55-57]$ ), emergence, lack of direct human access to reality (i.e., to the properties of systems), notions of state, event, and change.

Second, many of the changes introduced by BSO could be handled by appropriate qualifications or more precise specifications of the already existing notions (e.g., that concrete systems undergo change via energy transfer, but conceptual systems do not). The notion of things and their properties is still present, as some systems can be viewed as individual objects.

Thus, there is an important continuity between BSO and BWW - a continuity which is critical in assessing the status of impressive theoretical, conceptual and design research that stemmed from the ideas of Wand and Weber. Hence, BSO could still be used to posit that classes "tyrannize" instances [51] or that optional properties should be proscribed (although, in BSO, for concrete systems only, as conceptual systems do not follow the same principles as concrete ones).

On the other hand, BSO suggests a new way of thinking about reality, which is while somewhat compatible with the ideas in BWW, creates significant new openings for future research.

A more central role of systems carries profound implications beyond a mere potential for simplification of an ontology. In contrast to the emphasis on unique things BSO points a researcher and practitioner (e.g., in the context of conceptual modeling) to the 
importance of representing structure, relationship between systems, emergence, different levels, and interactions among sub-systems. In BSO, Bunge clearly wishes to balance his views between the value an individual-focused perspective may bring vs a perspective which is more sensitive to the whole. There have been many studies, including a number of recent ones, which followed early Bunge and emphasized the primacy of individuals (e.g., in the logical database design, conceptual modeling grammars, information quality, design collection processes, e.g., [19, 51, 58-60]). Bunge extensively talks about the limitations of the individual-focused perspective and suggests that a more balanced approach may be more fruitful, an approach which BSO appears to support better [44, 48].

Furthermore, BSO more than BWW enmeshed ontological issues with matters of epistemology, methodology, technology and ethics. It has provisions for social, mental and technological reality (including constructs such as social facts, concepts, hypotheses). These ideas stand to lessen many concerns raised earlier about Bunge related to the physicalist focus of his ontology. Furthermore, several studies used BWW to reason about notions of information and information quality $[12,19]$. However, BSO explicitly contains some of these constructs, and shows a path from the ontological primitive of a system to the notion of information, for example. Indeed, Bunge made a concerted effort to incorporate advances in modern information technology [41]. Thus, adopting BSO for future studies promises a more direct grounding of many important concepts of modern society into ideas of Bunge. In short, BSO stands to broadly enrich conceptual modeling and other IT related topics with many new ideas.

Considering the differences between earlier and more recent thinking of Bunge, we respond affirmatively to our research question and propose Bunge's Systemist Ontology or BSO, as a new ontology, and a new addition to the theoretical toolbox of IT.

\section{Conclusion}

Mario Bunge made a profound mark on the field of conceptual modeling, software engineering, information quality, database design. Much of this influence has been via BWW ontology - an incredibly valuable body of knowledge which popularized Bunge in the field of IT and became the foundation for numerous studies on design and use of information technologies. Even researchers who disagreed with aspects of BWW and Bunge's ontology, benefited from these ideas greatly, as BWW provided a key benchmark and inspired to pursue ontological studies in IT [4, 20, 21].

The significance and success of BWW motivated us to seek new ways Bunge's extensive thinking can be leveraged in the design and use of IT. As we showed in our work, BSO contains ideas that although somewhat compatible with BWW, are also quite different, raising new prospects and opening new possibilities.

The new BSO emerges as a complex and extensive set of beliefs. In this paper, we began to expose its basic tenets and assumptions. However, this work is by no means complete. Our key objective was to establish BSO as a new ontology. Much work remains to study BSO in its own right (including its benefits and limitations for applications in IT), formalizing it into a finite set of postulates (as Wand and Weber did for BWW), and seeking out areas of IT practice which could benefit from the application of these ideas. In short, we call on researchers to consider adopting BSO as a promising new ontology. 


\section{References}

1. Guerreiro, S., van Kervel, S.J., Babkin, E.: Towards devising an architectural framework for enterprise operating systems. In: ICSOFT, pp. 578-585 (2013)

2. Henderson-Sellers, B.: Why philosophize; why not just model? In: Johannesson, P., Lee, M.L., Liddle, S.W., Opdahl, A.L., López, Ó.P. (eds.) ER 2015. LNCS, vol. 9381, pp. 3-17. Springer, Cham (2015). https://doi.org/10.1007/978-3-319-25264-3_1

3. Gonzalez-Perez, C.: How ontologies can help in software engineering. In: Cunha, J., Fernandes, J.P., Lämmel, R., Saraiva, J., Zaytsev, V. (eds.) GTTSE 2015. LNCS, vol. 10223, pp. 26-44. Springer, Cham (2017). https://doi.org/10.1007/978-3-319-60074-1_2

4. Guizzardi, G.: Ontological foundations for structural conceptual models. Telematics Instituut Fundamental Research Series, Enschede, The Netherlands (2005)

5. Duarte, B.B., Falbo, R.A., Guizzardi, G., Guizzardi, R.S.S., Souza, V.E.S.: Towards an ontology of software defects, errors and failures. In: Trujillo, J.C., et al. (eds.) ER 2018. LNCS, vol. 11157, pp. 349-362. Springer, Cham (2018). https://doi.org/10.1007/978-3-030-008475_25

6. Lukyanenko, R., Larsen, K.R., Parsons, J., Gefen, D., Mueller, R.M.: Toward creating a general ontology for research validity. In: International Conference on Conceptual Modeling, Salvador, Brazil, pp. 133-137 (2019)

7. McDaniel, M., Storey, V.C.: Evaluating domain ontologies: clarification, classification, and challenges. ACM Comput. Surv. 53(1), 1-40 (2019)

8. Verdonck, M., Gailly, F., Pergl, R., Guizzardi, G., Martins, B., Pastor, O.: Comparing traditional conceptual modeling with ontology-driven conceptual modeling: an empirical study. Inf. Syst. 81, 92-103 (2019)

9. Recker, J., Rosemann, M., Krogstie, J.: Ontology-versus pattern-based evaluation of process modeling languages: a comparison. Commun. Assoc. Inf. Syst. 20(1), 48 (2007)

10. Martínez Ferrandis, A.M., Pastor López, O., Guizzardi, G.: Applying the principles of an ontology-based approach to a conceptual schema of human genome. In: Ng, W., Storey, V.C., Trujillo, J.C. (eds.) ER 2013. LNCS, vol. 8217, pp. 471-478. Springer, Heidelberg (2013). https://doi.org/10.1007/978-3-642-41924-9_40

11. Pastor, Ó., España, S., González, A.: An ontological-based approach to analyze software production methods. In: Kaschek, R., Kop, C., Steinberger, C., Fliedl, G. (eds.) UNISCON 2008. LNBIP, vol. 5, pp. 258-270. Springer, Heidelberg (2008). https://doi.org/10.1007/9783-540-78942-0_26

12. Wand, Y., Wang, R.Y.: Anchoring data quality dimensions in ontological foundations. Commun. ACM 39(11), 86-95 (1996)

13. Reinhartz-Berger, I., Itzik, N., Wand, Y.: Analyzing variability of software product lines using semantic and ontological considerations. In: Jarke, M., et al. (eds.) CAiSE 2014. LNCS, vol. 8484, pp. 150-164. Springer, Cham (2014). https://doi.org/10.1007/978-3-319-07881-6_11

14. Guarino, N.: Formal ontology, conceptual analysis and knowledge representation. Int. J. Hum. Comput. Stud. 43(5-6), 625-640 (1995)

15. Bodart, F., Patel, A., Sim, M., Weber, R.: Should optional properties be used in conceptual modelling? A theory and three empirical tests. Inf. Syst. Res. 12(4), 384-405 (2001)

16. Burton-Jones, A., Weber, R.: Building conceptual modeling on the foundation of ontology. In: Computing Handbook: Information Systems and Information Technology, pp. 15.1-15.24. CRC Press, Boca Raton (2014)

17. Bera, P., Burton-Jones, A., Wand, Y.: Research note-how semantics and pragmatics interact in understanding conceptual models. Inf. Syst. Res. 25(2), 401-419 (2014)

18. Recker, J., Rosemann, M., Green, P., Indulska, M.: Do ontological deficiencies in modeling grammars matter? MIS Q. 35(1), 57-79 (2011) 
19. Lukyanenko, R., Parsons, J., Wiersma, Y.: The IQ of the crowd: understanding and improving information quality in structured user-generated content. Inf. Syst. Res. 25(4), 669-689 (2014)

20. Guizzardi, G., Wagner, G., Almeida, J.P.A., Guizzardi, R.S.: Towards ontological foundations for conceptual modeling: the unified foundational ontology (UFO) story. Appl. Ontol. 10(3-4), 259-271 (2015)

21. March, S.T., Allen, G.N.: Toward a social ontology for conceptual modeling. In: Communications of the AIS, vol. 34 (2014)

22. Herre, H.: General formal ontology (GFO): a foundational ontology for conceptual modelling. In: Poli, R., Healy, M., Kameas, A. (eds.) Theory and Applications of Ontology: Computer Applications, pp. 297-345. Springer, Heidelberg (2010). https://doi.org/10.1007/978-90-4818847-5_14

23. Gangemi, A., Guarino, N., Masolo, C., Oltramari, A., Schneider, L.: Sweetening ontologies with DOLCE. In: Gómez-Pérez, A., Benjamins, V.R. (eds.) EKAW 2002. LNCS (LNAI), vol. 2473, pp. 166-181. Springer, Heidelberg (2002). https://doi.org/10.1007/3-540-45810-7_18

24. Wand, Y., Weber, R.: Toward a theory of the deep structure of information systems. In: International Conference on Information Systems, Copenhagen, Denmark, pp. 61-71 (1990)

25. Wand, Y., Weber, R.: An ontological analysis of some fundamental information systems concepts. In: Proceedings of the Ninth International Conference on Information Systems, vol. 1988, pp. 213-226 (1988)

26. Wand, Y., Weber, R.: Thirty years later: some reflections on ontological analysis in conceptual modeling. J. Database Manag. (JDM) 28(1), 1-17 (2017)

27. Burton-Jones, A., Recker, J., Indulska, M., Green, P., Weber, R.: Assessing representation theory with a framework for pursuing success and failure. MIS Q. 41(4), 1307-1333 (2017)

28. Wyssusek, B.: On ontological foundations of conceptual modelling. Scand. J. Inf. Syst. 18(1), 63-80 (2006)

29. Bunge, M.A.: Treatise on Basic Philosophy: Ontology I: The Furniture of The World. Reidel, Boston (1977)

30. Bunge, M.A.: Treatise on Basic Philosophy: Ontology II: A World of Systems. Reidel Publishing Company, Boston (1979)

31. Bunge, M.A., et al.: Mario Bunge: A Centenary Festschrift. Springer, Cham (2019). https:// doi.org/10.1007/978-3-030-16673-1

32. Rosemann, M., Wyssusek, B.: Enhancing the expressiveness of the Bunge-Wand-Weber ontology. In: AMCIS 2005 Proceedings, pp. 1-8 (2005)

33. Wand, Y., Weber, R.: On the ontological expressiveness of information systems analysis and design grammars. Inf. Syst. J. 3(4), 217-237 (1993)

34. Wand, Y., Weber, R.: Mario Bunge's ontology as a formal foundation for information systems concepts. In: Weingartner, P., Dorn, G. (eds.) Rodopi, pp. 123-150 (1990)

35. Jabbari, M., Lukyanenko, R., Recker, J., Samuel, B., Castellanos, A.: Conceptual modeling research: revisiting and updating Wand and Weber's 2002 research agenda. In: AIS SIGSAND, pp. 1-12 (2018)

36. Saghafi, A., Wand, Y.: Conceptual models? A meta-analysis of empirical work. In: Hawaii International Conference on System Sciences, Big Island, HI, pp. 1-15 (2014)

37. Veres, C., Mansson, G.: Psychological foundations for concept modeling. In: Blackwell, A.F., Marriott, K., Shimojima, A. (eds.) Diagrams 2004. LNCS (LNAI), vol. 2980, pp. 26-28. Springer, Heidelberg (2004). https://doi.org/10.1007/978-3-540-25931-2_5

38. Bunge, M.A.: Chasing reality: strife over realism. University of Toronto Press, Toronto (2006)

39. Bunge, M.A.: Treatise on Basic Philosophy: Ethics: The Good and The Right. Springer, Amsterdam (1989). https://doi.org/10.1007/978-94-009-2601-1

40. Bunge, M.A.: Between Two Worlds: Memoirs of a Philosopher-Scientist. Springer, Heidelberg (2016). https://doi.org/10.1007/978-3-319-29251-9 
41. Bunge, M.A.: The dark side of technological progress. In: Sassower, R., Laor, N. (eds.) The Impact of Critical Rationalism, pp. 109-113. Springer, Cham (2019). https://doi.org/10.1007/ 978-3-319-90826-7_10

42. Bunge, M.A.: Treatise on Basic Philosophy: Semantics I: Sense and Reference. Springer, Amsterdam (1974). https://doi.org/10.1007/978-94-010-9920-2

43. Bunge, M.A.: Treatise on Basic Philosophy: Volume 6: Epistemology \& Methodology II: Understanding the World. Reidel, Boston (1983)

44. Bunge, M.A.: Finding Philosophy in Social Science. Yale University Press, New Haven (1996)

45. Bunge, M.A.: Philosophy of Science: Volume 2, From Explanation to Justification. Routledge, New York (2017)

46. Bunge, M.A.: Systems everywhere. In: Cybernetics and Applied Systems, pp. 23-41. CRC Press, London (2018)

47. Bunge, M.A.: Emergence and Convergence: Qualitative Novelty and the Unity of Knowledge. University of Toronto Press, Toronto (2003)

48. Bunge, M.A.: Systemism: the alternative to individualism and holism. J. Soc. Econ. 2(29), 147-157 (2000)

49. Bunge, M.A.: Gravitational waves and spacetime. Found. Sci. 23(2), 399-403 (2018). https:// doi.org/10.1007/s10699-017-9526-y

50. Agazzi, E.: Systemic thinking. In: Matthews, M.R. (ed.) Mario Bunge: A Centenary Festschrift, pp. 219-240. Springer, Cham (2019). https://doi.org/10.1007/978-3-030-16673$1 \_13$

51. Parsons, J., Wand, Y.: Emancipating instances from the tyranny of classes in information modeling. ACM Trans. Database Syst. 25(2), 228-268 (2000)

52. Hirst, R.J.: The Problems of Perception. Routledge, London (2002)

53. Hempel, C.G.: Philosophy of Natural Science. Pearson, London (1966)

54. Milton, S.K.: Ontological foundations of representational information systems. Scand. J. Inf. Syst. 19(1), 5 (2007)

55. Bodart, F., Weber, R.: Optional properties versus subtyping in conceptual modeling: a theory and empirical test. In: International Conference on Information Systems (1996)

56. Burton-Jones, A., Weber, R.: Properties do not have properties: investigating a questionable conceptual modeling practice. In: Annual Symposium on Research in Systems Analysis and Design (2003)

57. Gemino, A., Wand, Y.: Complexity and clarity in conceptual modeling: comparison of mandatory and optional properties. Data Knowl. Eng. 55(3), 301-326 (2005)

58. Lukyanenko, R., Parsons, J., Wiersma, Y.F., Wachinger, G., Huber, B., Meldt, R.: Representing crowd knowledge: guidelines for conceptual modeling of user-generated content. J. Assoc. Inf. Syst. 18(4), 297-339 (2017)

59. Lukyanenko, R., Parsons, J., Samuel, B.M.: Representing instances: the case for reengineering conceptual modeling grammars. Eur. J. Inf. Syst. 28(1), 68-90 (2019). https://doi.org/10.1080/ 0960085X.2018.1488567

60. Samuel, B.M., Khatri, V., Ramesh, V.: Exploring the effects of extensional versus intentional representations on domain understanding. MIS Q. 42(4), 1187-1209 (2018) 